\title{
FREQUENCIA DE MUCOCELES EM CRIANÇAS E ADOLESCENTES: ESTUDO RETROSPECTIVO DE 15 ANOS
}

Marta Aparecida Alberton NUERNBERG, Karine LYKO, Cassius Carvalho TORRES-PEREIRA, Cleto Mariosvaldo PIAZETTA, José Miguel AMENÁBAR

Mucoceles são lesões benignas associadas à ruptura de ductos da glândula salivar originando o fenômeno de extravasamento de muco. Esse relato pretende descrever a frequência de mucoceles em crianças e adolescentes atendidos na clínica de estomatologia da UFPR num período de 15 anos. Pacientes atendidos entre 1994 a 2009 tiveram seus prontuários revisados, sendo incluídos pacientes com idade entre 0 a 18 anos e com diagnóstico de mucocele, resultando num total de 172 casos. A média de idade foi de 11 anos ( \pm 4 anos), sendo que $90 \%$ dos pacientes tinham entre 7 e 18 anos e $78 \%$ eram brancos. Dentre os pacientes 81 eram do sexo masculino e 91 do feminino. Quanto à localização foi encontrado em mucosa labial inferior (85\%), ventre de língua (9\%), mucosa jugual $(4 \%)$ e palato mole $(2 \%)$. Diagnóstico histológico e clínico foi realizado em $(69 \%)$ dos casos e apenas clínico em (31\%). Os pacientes foram encaminhados pela Secretaria Municipal de Curitiba (83\%), Secretarias Municipais da Região Metropolitana (10\%) e dentista particular (4\%). Os resultados demonstraram que não houve predileção por sexo, a localização mais freqüente foi em mucosa labial inferior e a principal forma de diagnóstico utilizada foi o exame histológico associado ao clínico.

Palavras-chave: Mucocele; odontopediatria; odontologia. 